\title{
Longevidade de hastes florais de Oncidium baueri mantidas em soluções conservantes
}

\author{
Vanessa Favetta*, Ronan Carlos Colombo, Ricardo Tadeu de Faria
}

Universidade Estadual de Londrina, Londrina, PR, Brasil

Autor correspondente, e-mail: vanfavetta@hotmail.com

\section{Resumo}

As orquídeas vêm ganhando destaque no mercado de flores de corte devido ao exotismo e a beleza singular de suas flores. No entanto, técnicas que contribuam para manter a qualidade floral são necessárias, visto que o sucesso comercial está atrelado à longevidade das flores quando cortadas. Assim, o objetivo do trabalho foi avaliar soluções conservantes na longevidade póscolheita de hastes florais de Oncidium baveri. Hastes florais, com $60 \mathrm{~cm}$ de comprimento e $90 \%$ das flores abertas, foram submetidas ao pré-tratamento em solução de pulsing à base de sacarose, por 12 ou 24 horas e distribuídas em soluções de manutenção contendo sacarose e/ou Flower ${ }^{\circledR}$, mantendo-se um tratamento controle em água destilada. Essas soluções foram acrescidas de 0,5\% de hipoclorito de sódio. A avaliação para verificar a qualidade das flores foi realizada diariamente por meio de um critério de notas, variando de 4 a 0 . A partir do terceiro dia de avaliação, as hastes florais submetidas ao pré-tratamento em solução de pulsing apresentaram média estatisticamente inferior e, no quarto dia de avaliação foram consideradas inadequadas à comercialização. Maior longevidade e qualidade das flores podem ser obtidas mantendo-se as hastes em água destilada ou em solução de manutenção a base de sacarose a $1 \%$.

Palavras-chave: flor de corte, Orchidaceae, pós-colheita, pulsing.

Floral stems longevity of Oncidium baueri kept in preservative solutions

\begin{abstract}
Orchids have been gaining prominence in the cut flower market due to the exoticism and the singular beauty of its flowers. However, techniques which help to keep the floral quality are needed, since the commercial success is tied to the flowers longevity after cut. Thus, the aim of this study was to evaluate preservative solutions on postharvest longevity of Oncidium baveri floral stems. Floral stems, with $60 \mathrm{~cm}$ of length and $90 \%$ of open flowers were submitted to pretreatment in a pulsing solution, sucrose-based, for 12 and 24 hours, and placed in maintenance solutions containing sucrose and/or Flower $r^{\oplus}$; keeping the control treatment, with distilled water only. These solutions were added with $0.5 \%$ of sodium hypochlorite. The evaluation to verify the quality of the flowers was performed daily using a criterion of notes, ranging from 4 to 0 . From third day of evaluation, the floral stems submitted to pretreatment with pulsing solution presented statistically lower averages and at the fourth day of evaluation were considered inadequate for marketing. Increased longevity and quality of the flowers can be obtained by keeping the floral stems in distilled water or in maintenance solutions, which are $1 \%$ sucrose-based.
\end{abstract}

Keywords: cut flower, Orchidaceae, postharvest, pulsing. 


\section{Introdução}

O sucesso comercial de uma flor de corte depende, principalmente, de sua qualidade estética, sistema de produção e longevidade após a colheita. O manuseio inadequado na fase de pós-colheita encontra-se dentre os principais problemas da floricultura brasileira (Coelho et al., 2012), respondendo pela perda de 20 a $30 \%$ das flores de corte comercializadas (Han, 2002).

O controle da senescência é um processo que varia entre espécies e requer a otimização das relações hídricas, redução da abscisão ou murcha das pétalas e flores, controle do crescimento dos microrganismos, e em muitos casos, o fornecimento de substratos respiratórios (Finger et al., 2004). Entretanto, existem técnicas de conservação específicas, que contribuem para manter a qualidade floral pós-colheita. Dentre essas técnicas, destacam-se as soluções de pulsing, que consistem em um pré-tratamento, antes do transporte ou armazenamento, que prolonga a vida das flores, mesmo após a transferência para a água ou para as soluções de manutenção (Halevy \& Mayak, 1981). Essas soluções podem ser compostas de açúcares, ácidos orgânicos, inibidores da síntese ou ação do etileno e/ou bactericidas (Dias-Tagliacozzo et al., 2005).

A solução de pulsing à base de sacarose tem se mostrado eficiente para o pré-tratamento de espécies como Zantedeschia aethiopica (Almeida et al., 201 1.), Limonium sinuatum (Ciotta \& Nunes, 2011), Epidendrum ibaguense (Moraes et al., 2007) e Lilium longiflorum (Barbosa et al., 2006), no entanto, o efeito benéfico depende da concentração e do tempo de exposição, variando entre as espécies.

Além da imersão das hastes florais em solução de pulsing, é importante, após esse pré-tratamento, acondicioná-las em água pura ou em solução de manutenção para preservar a turgescência das flores; sendo comum o uso de soluções à base de germicidas e sacarose. Além desses, o emprego de reguladores de crescimento (Macnish et al., 2010; Bellé et al., 2004) e inibidores da síntese de etileno (Mapeli et al., 2009; Finger et al., 2004) tem sido estudado há vários anos como preservantes florais.
Ainda é possível encontrar no mercado produtos formulados (preservantes florais), utilizados no preparo de solução de vaso, para a manutenção das hastes florais. Dentre eles, Flower ${ }^{\circledR}$ se destaca por conter em sua composição carboidratos, antioxidantes, bactericidas, algicidas e fungicidas.

Das flores cortadas, as orquídeas vêm ganhando destaque nos últimos anos devido à beleza peculiar, cores vibrantes e longevidade pós-colheita, em especial, algumas espécies dos gêneros Phalaenopsis (Hansen et al., 2012) e Oncidium (Faria \& Colombo, 2015; Mattiuz et al., 2012; Huang \& Paull, 2009). A espécie brasileira Oncidium baveri possui um alto potencial ornamental, o que pode favorecer sua aceitação no mercado como flor cortada. Sua inflorescência apresenta flores amarelas, distribuídas em hastes que chegam a quatro metros de comprimento (Faria et al., 2006). Contudo, são escassos estudos acerca da produção dessa espécie para comercialização como flor de corte e tratamento das hastes florais na etapa de pós-colheita.

Assim, objetivou-se avaliar a longevidade pós-colheita de hastes florais de $O$. baveri mantidas em soluções conservantes.

\section{Material e Métodos}

Hastes florais de $O$. baveri recémcolhidas e com $90 \%$ das flores abertas foram selecionadas quanto à sanidade, padronizadas com $60 \mathrm{~cm}$ de comprimento e submetidas às seguintes soluções conservantes: T1 lágua destilada); T2 (sacarose a 1\%); T3 (Flower $^{\circledR}$ a $1,7 \%$ ); T4 (sacarose a $1 \%$ + Flower $^{\circledR}$ a 1,7\%); T5 (pulsing $12 \mathrm{~h}+$ sacarose a 1\%); T6 (pulsing $12 \mathrm{~h}+$ Flower ${ }^{\circledR}$ a 1,7\%); T7 (pulsing $12 \mathrm{~h}+$ sacarose a $1 \%+$ Flower ${ }^{\circledR}$ a 1,7\%); 18 (pulsing $24 \mathrm{~h}+$ sacarose a 1\%); T9 (pulsing $24 \mathrm{~h}+$ Flower $^{\circledR}$ a 1,7\%) e T10 (pulsing $24 \mathrm{~h}+$ sacarose a $1 \%+$ Flower $^{\circledR}$ a 1,7\%). A dose utilizada de Flower $^{\circledR}$ foi a recomendada pelo fabricante. A solução de pulsing foi composta por água destilada + sacarose (10\%) e a todas as soluções foi acrescido $0,5 \%$ de hipoclorito de sódio (2,5\%).

O delineamento experimental consistiu em arranjo inteiramente casualizado, com 10 tratamentos e cinco repetições, tendo- 
se uma haste por repetição. As hastes foram acondicionadas em frascos de vidro contendo $200 \mathrm{~mL}$ de solução conservante, trocada a cada dois dias; junto à troca das soluções, cortava-se a base das hastes ( $1 \mathrm{~cm}$, aproximadamente) para evitar a possível obstrução dos vasos condutores devido ao desenvolvimento de eventuais microrganismos. Os frascos foram mantidos sob temperatura de $25^{\circ} \mathrm{C} \pm 1$ e iluminação constante.

As avaliações das flores aconteceram diariamente seguindo-se o critério de notas de 4 a 0 adaptado de Castro (1984), com avaliações em três flores da base, três da porção mediana e três do ápice das hastes. As notas atribuídas à qualidade das flores foram: Nota 4 (flor túrgida), Nota 3 (pétalas túrgidas e perda de turgescência do labelo), Nota 2 (pétalas e labelo pouco túrgidos), Nota 1 (perda total de turgescência do labelo) e Nota 0 (dobramento das bordas e início do fechamento) (Figura 1). As médias das notas obtidas foram estatisticamente analisadas e comparadas pelo teste de Kruskal-Wallis e Student-Newman-Keuls a 5\% de significância.

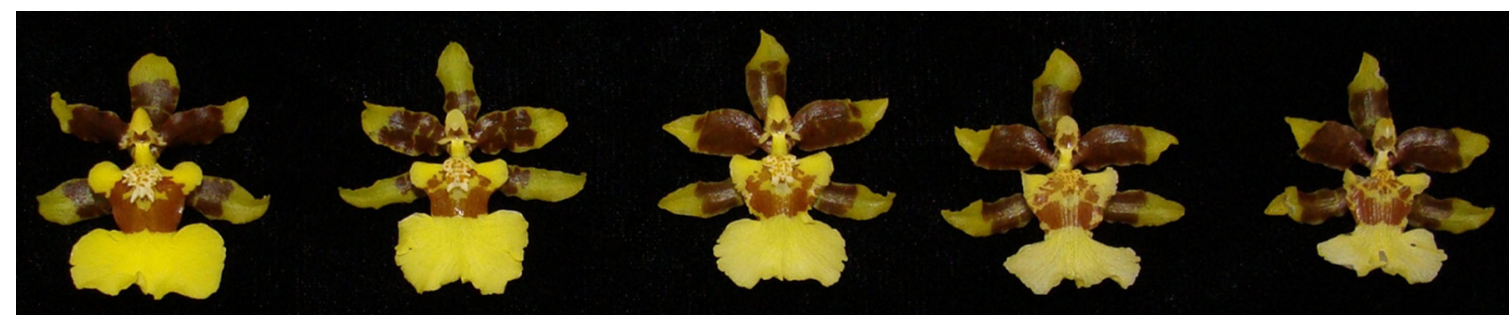

Figura 1. Critério de notas adaptado de Castro (1984) para a avaliação de flores; notas da esquerda para a direita (4; 3; 2; 1 e 0)

\section{Resultados e Discussão}

A Tabela 1 apresenta as notas médias para as flores de inflorescências de Oncidium baveri mantidas em soluções conservantes. No primeiro dia de avaliação (Dia 1) não havia diferença entre as flores, devido à padronização das mesmas após a colheita. No entanto, observa-se que a partir do segundo dia de avaliação (Dia 2), as flores submetidas ao prétratamento em solução de pulsing por 12 e 24 horas apresentaram notas inferiores, apesar de não diferirem estatisticamente, exceto T6 (pulsing $12 \mathrm{~h}+$ Flower $^{\oplus}$ a $1,7 \%$ ) que diferiu dos tratamentos sem pulsing.

Tabela 1. Nota média (posto médio) para a qualidade de flores de inflorescências de Oncidium baueri submetidas a soluções conservantes.

\begin{tabular}{|c|c|c|c|c|c|c|}
\hline Tratamentos* & Dia 1 & Dia 2 & Dia 3 & Dia 4 & Dia 5 & Dia 6 \\
\hline $\mathrm{Tl}$ & $4,0 a^{* *}$ & $4,0(33,0) a$ & $3,8(39,0) a$ & $3,0(41,5) a$ & $2,4(42,6) a$ & $1,8(42,1) a$ \\
\hline T2 & $4,0 \mathrm{a}$ & $4,0(33,0) \mathrm{a}$ & $3,8(39,0)$ a & $3,0(41,5)$ a & $2,4(42,6) \mathrm{a}$ & $1,4(39,3) a b$ \\
\hline T3 & $4,0 a$ & $4,0(33,0) a$ & $3,4(32,0) a b c$ & $2,4(31,9) a b$ & $1,2(28,6) a b c$ & $0,4(23,2) b c$ \\
\hline T4 & $4,0 a$ & $4,0(33,0) a$ & $3,6(35,5) a b$ & $2,6(35,1) a b$ & $1,6(33,8) a b$ & $1,0(31,1) a b c$ \\
\hline T5 & $4,0 a$ & $3,6(23,2) a b$ & $2,6(18,4) \mathrm{bcd}$ & $1,8(22,6) \mathrm{bc}$ & $0,4(16,4) b c$ & $0,0(15,0) c$ \\
\hline T6 & $4,0 a$ & $3,2(13,4) b$ & $2,2(11,8) \mathrm{d}$ & $1,2(13,1) \mathrm{C}$ & $0,2(13,2) c$ & $0,2(19,1) \mathrm{C}$ \\
\hline $\mathrm{T} 7$ & $4,0 a$ & $3,6(23,2) a b$ & $2,6(18,4) \mathrm{bcd}$ & $1,8(22,5) \mathrm{bc}$ & $1,0(24,0) \mathrm{bc}$ & $0,6(21,9) b c$ \\
\hline T8 & $4,0 a$ & $3,4(18,3) a b$ & $2,4(15,1) \mathrm{cd}$ & $1,2(13,1) \mathrm{C}$ & $0,2(13,2) c$ & $0,0(15,0) c$ \\
\hline T9 & $4,0 a$ & $3,8(28,1) a b$ & $3,2(28,7) \mathrm{abcd}$ & $1,8(22,4) \mathrm{bc}$ & $1,2(27,4) a b c$ & $0,8(29,2) a b c$ \\
\hline $\mathrm{T} 10$ & $4,0 \mathrm{a}$ & $3,2(16,8) a b$ & $2,4(17,1) \mathrm{cd}$ & $1,0(11,3) \subset$ & $0,2(13,2) \mathrm{C}$ & $0,2(19,1) \mathrm{C}$ \\
\hline
\end{tabular}

Influências diretas na longevidade pós-colheita das flores não foram observadas quando essas foram submetidas aos tratamentos contendo o preservante floral Flower ${ }^{\circledR}$, o que implica a não necessidade de uso do produto. Almeida et al. (2008) não observaram diferenças significativas na longevidade de flores de copo de leite mantidas em solução à base de Flower ${ }^{\circledR}$ a 1,4\%, corroborando com o resultado verificado no presente trabalho.

Diferenças significativas nas notas médias, entre os tratamentos em que as hastes florais foram mantidas em solução de pulsing e os demais, foram observadas a partir do terceiro 
dia de avaliação. Nesse caso, as inflorescências podem ter perdido água para a solução do vaso e assim, perdido a turgidez; isso, devido ao aumento do potencial osmótico do meio, causado pela adição de sacarose (10\%) na solução de pulsing. Hastenreiter et al. (2006), avaliando longevidade floral em Oncidium varicosum, também verificaram que a solução de pulsing (15\%) não prolongou a vida de vaso da orquídea estudada.

Ainda de acordo Halevy \& Mayak (1981) nos tratamentos com pulsing a concentração de açúcar pode chegar a mais de $20 \%$; porém, em alguns casos, a sacarose pode causar efeito adverso (HAN, 2002). Moraes et al. (1999) relatam que a sacarose, nas concentrações de $1 \%$ a $2 \%$, em solução conservante foi responsável pela plasmólise e morte do tecido de folhas em rosas cortadas.

Brackmann et al. (2000) trabalhando com soluções conservantes na pós-colheita de crisântemo, observaram que a solução com sacarose facilitou a abertura dos botões florais e atribuem este fato ao possível aumento da respiração, visto que esse carboidrato é substrato para esse processo metabólico. Nesse caso, a presença de sacarose nas soluções de pulsing também pode ter aumentado a taxa respiratória e acelerado o pico climatérico em O. baveri, levando à senescência precoce das hastes florais.

Além disso, a alta concentração de sacarose, na solução de pulsing, pode ter favorecido o desenvolvimento de microrganismos e consequente obstrução dos vasos condutores; mesmo diante do uso de hipoclorito e corte da base das hastes a cada dois dias. Pois, substâncias como sacarose e glicose são utilizadas por microrganismos como substratos para o seu desenvolvimento (DiasTagliacozzo et al., 2005).

A partir do quarto dia de avaliação verificou-se perda de qualidade comercial das inflorescências submetidas ao pré-tratamento com solução de pulsing, visto que ao atingirem a nota 2 (pétalas e labelo pouco túrgidos), ou inferior, as flores não apresentam mais potencial para comercialização.

Em suma, pôde ser observado que a imersão das hastes florais em solução de pulsing reduziu a longevidade e qualidade das flores de O. baveri. No entanto, nos tratamentos $\mathrm{Tl}$ (água destilada) e T2 (sacarose a 1\%) as inflorescências se mantiveram túrgidas por quatro dias.

\section{Conclusões}

O pré-tratamento com solução de pulsing acelera a senescência de hastes florais de O. baveri.

A manutenção das hastes em água destilada (T1) e solução de sacarose a 1\% (T2) propiciam maior longevidade e das flores de $O$. baveri.

\section{Referências}

Almeida, E.F.A., Paiva, P.D.O., Lima, L.C.O., Resende, M.L, Tavares, T.S. 2008. Pós-colheita de copo-de-leite: efeito de diferentes conservantes comerciais e armazenamento a frio. Ciência e Agrotecnologia 32: 1189-1194.

Almeida, E.F.A., Paiva, P.D.O., Lima, L.C.O., Silva, F.C., Fonseca, J., Nogueira, D.A. 2011. Calla lily inflorescences postharvest: pulsing with different sucrose concentrations and storage conditions. Ciência e Agrotecnologia 25: 657-663.

Barbosa, J.G., Medeiros, A.R.S., Finger, F.L., Reis, F.P., Álverez, V.S., Barbosa, M.S. 2006. Longevidade de inflorescências de lírio, de diferentes estádios de colheita, pré-tratadas com sacarose e tiossulfato de prata (STS). Ciência Rural 36: 99-14.

Bellé, R.A., Mainardi, J.C.C.T., Mello, J.B., Zachet, D. 2004. Abertura floral de Dendranthema grandiflora Tzvelev. 'Bronze Repin' após armazenamento a frio seguido de "pulsing". Ciência Rural 34: 63-70.

Brackmann, A., Bellé, R.A., Vizzotto, M., Lunardi, R. 2000. Armazenamento de crisântemos Dedranthema grandiflora $\mathrm{cv}$. Red refocus em diferentes temperaturas e soluções conservantes. Revista Brasileira de Agrociência 6: 19-23.

Castro, C.E.F. 1984. Tratamentos químicos póscolheita e critérios de avaliação de qualidade de cravos Dianthus caryophyllus cv. Scania Red Sim. 139p. (Dissertação de Mestrado) Escola Superior de Agricultura Luiz de Queiroz, Piracicaba, Brasil.

Ciotta, M.N., Nunes, E.C. 2011. Tratamentos pós-colheita e qualidade de hastes florais de Limonium sinuatum. Revista Brasileira de Horticultura Ornamental 17: 159-166.

Coelho, L.L., Carneiro, D.N.M., Paiva, P.D., 
Carneiro, L.F. 2012. Soluções conservantes e pulsing na pós-colheita de Zingiber spectabile. Pesquisa Agropecuária Tropical 42: 482-485.

Dias-tagliacozzo, G.M., Finger, F.L., Barbosa, J.G. 2005. Fisiologia pós-colheita de flores de corte. Revista Brasileira Horticultura Ornamental 11: 8999.

Faria, R.T., Colombo, R.C. 2015. Oncidium: a orquídea em expansão no cenário florícola. Horticultura Brasileira 33(4): 533-533.

Faria, R.T., Dalio, R.J.D., Unemoto, L.K., Silva, G.L. 2006. Propagação in vitro de Oncidium baveri Lindl. (Orchidaceae) sem uso de ágar. Acta Scientiarum Agronomy 28: 71-74.

Finger, F.L., Carneiro, T.F., Barbosa, J.G. 2004. Senescência pós-colheita de inflorescências de esporinha (Consolida ajacis). Pesquisa agropecuaria brasileira 39: 533-537.

Halevy, A.H., Mayak, S. 1981. Senescence and postharvest physiology of cut flowers. Horticultural Reviews 3: 59-143.

Han, S.S. Postharvest handling of six more fieldgrown cut flowers\&mdash;Astilbe, Gladiolus, Helianthus, Liatris, Lilium, Zinnia. 2002. https:// ag.umass.edu/fact-sheets/postharvest-handlingof-six-more-field-grown-cut-flowers-astilbegladiolus-helianthus. Acesso em 16 Fev. 2016.

Hansen, M.M., Müller, R., Lütken, H. 2012. Effect of the ethylene inhibitor 1-mcp in postharvest chains of mini-Phalaenopsis. Acta Horticulturae 970: 205-211.

Hastenreiter, F.A, Vieira, J.G, Faria, R.T. 2006. Longevidade pós-colheita de flores de Oncidium varicosum (Orchidaceae). Semina: Ciências Agrárias 27: 27-34.

Huang, C.C., PAULL, R.E. 2009. The responses of Oncidium cut flowers to ethylene and 1-MCPl. Journal Taiwan Agriculture Research 58:1-6.

Macnish, A.J., Jiang, C.Z., Reid, M.S. 2010. Treatment with thidiazuron improves opening and vase life of iris flowers. Postharvest Biology and Technology 56: 77-84.

Mapeli, A.M., Finger, F.L., Oliveira, L.S., Barbosa, J.G. 2009. Longevidade de inflorescências de Epidendrum ibaguense tratadas com aminoetoxivinilglicina. Pesquisa agropecuária brasileira 44: 258-262.

Mattiuz, C.F.M., Mattiuz, B.H., Rodrigues, T.J.D., Pietro, J., Martins, R.N., Grossi, S.F. 2012. Longevity of Oncidium varicosum (Orchidaceae) inflorescences treated with 1methylciclopropene. Ciência Rural 42: 987-992.
Moraes, P.J., Cecon, P.R., Finger, F.L., Barbosa, J.G., Alvares, V.S. 1999. Efeito da refrigeração e do condicionamento em sacarose sobre a longevidade de inflorescências de Strelitzia reginae Ait. Revista Brasileira de Horticultura Ornamental 5:151-156.

Moraes, P.J., Finger, F.L., Barbosa, J.G., Cecon, P.R. 2007. Longevidade pós-colheita da orquídea Epidendrum ibaguense. Revista Brasileira de Horticultura Ornamental 13: 31-37. 